\title{
Staphylococcus aureus Contamination during Food Preparation, Processing and Handling
}

\author{
Al-Bahry S. N., Mahmoud I. Y., Al-Musharafi S. K., and Sivakumar N.
}

\begin{abstract}
Throughout the world, food processing and handling is a major problem leading to food poisoning and infection. A total of 480 samples was analyzed for Staphylococcus aureus contamination which resulted from food processing. Most of the isolates were taken from food-handlers using nasal swabs. The most contaminated food was chicken pastries, followed by egg sandwiches and spring rolls. Isolates from all samples produced virulence factors hemolysin, coagulase, DNase and enterotoxins. Five different enterotoxins (SEs) were isolated and identified from different samples. The detected SEs are SEA to SEE. Most the isolates secreted SEA followed by SEB. The strains were multiple-resistant to several antibiotics. Ampicillin and penicillin were the most resisted antibiotics. The value of this investigation is to generate awareness about the dangers of food processing and handling leading to infections by foodborne microbes which constitute a potential health risk for the consumers.
\end{abstract}

Index Terms-Staphylococcus aureus, contamination, food products, food handlers.

\section{INTRODUCTION}

Food processing is an important industry worldwide. One of the major problems threatening food industry is the contamination with foodborne microbes of human origin resulting from improper handling and processing. Microbial contamination reduces shelf life and food quality leading to food infection and poisoning outbreaks, some of which are life threatening. Continuous monitoring of food processing is essential to avoid potential health problems.

Staphylococcus aureus is one of the major foodborne pathogens, frequently causing diseases globally as a result of food ingestion contaminated with staphylococcal toxin [1].

$S$. aureus is characterized by its ability to produce enterotoxins [2], which are considered to be the main causative agents of staphylococcal food poisoning [1]. S. aureus are commonly found on the skin of mammals, birds and fomites [2]. Humans are considered to be the major source of staphylococcal food poisoning [3]. S. aureus is found in nasal passages, throat, hair and skin of carriers [2]. Food is usually contaminated from nasal secretions, sneezing, coughing and direct hand contact of infected carriers [4], [5].

Three categories of $S$. aureus carriers have been

Manuscript received November 9, 2013; revised February 21, 2014.

Al-Bahry S. N. and Sivakumar N. are with the Department of Biology, College of Science, Sultan Qaboos University, Oman (e-mail: snbahry@squ.edu.om, apnsiva@squ.edu.om)

Mahmoud I. Y. is with the Department of Biological Sciences and Chemistry, University of Nizwa, Oman (e-mail: ibrahim.younis@unizwa.edu.om)

Al-Musharafi S. K. is with the Department of Applied Biotechnology, Sur College of Applied Sciences, Sur, Oman (e-mail: salma.sur@ cas.edu.om). recognized: persistent, intermittent (occasional) and never-carriers. Persistent carriers are infected with the same staphylococcal strain for months or even years. It was reported that $20 \%-35 \%$ are persistent carriers. In addition, intermittent carriers represent $40 \%-70 \%$, while never-carriers are uninfected representing $10 \%-40 \%$ of the population [6], [7].

$S$. aureus secretes several virulence factors and extracellular toxins of protein origin which contributes to the pathogenicity. It is the only species that produces beta hemolysin which lyse red blood cells at cold temperature [6]

Unlike other foodborne illnesses, staphylococcal food poisoning occurs shortly after, $30 \mathrm{~min}$ to $8 \mathrm{hrs}$, food ingestion contaminated with enterotoxin. Several symptoms result from SEs ingestion, which include abdominal cramping, vomiting, diarrhea, nausea, and chills. Infected individuals usually recover from the toxicity within $24-48 \mathrm{hrs}$ [1].

SEs are pyrogenic toxins of the superantigen family due to their structural relatedness and their biological activities [8] SEs are heat-stable at higher temperatures [2]. Serologically the toxins are classifed into many types. The most common types are SEA, SEB, SEC, SED and SEE [9]. Other studies reported the existence of other types, such as SEG, SEI, SEH, SEK, SER and SET [1], [10]-[12].

Although the physiological stresses that stimulate secretion of SEs are not well understood, production of SEs occurs as a result of specific environmental stimulants present in food Appropriate temperature, $\mathrm{NaCl}$ concentrations and $\mathrm{pH}$ are important factors affecting both growth and secretion of $S$. aureus enterotoxins [13], [14]. For example, growth of $S$. aureus declined with lower $\mathrm{pH}$ values [14]. Moreover, $S$. aureus can tolerate high osmotic sugar and salt concentrations.

SEs stability in high temperature has been well established. Temperature used in cooking is insufficient to destroy the SEs even after the microbe has been eradicated in food by cooking. The SEs in food are difficult to distinguish due to its lack of taste and food appearance [2].

Pathogenicity of $S$. aureus is related to its ability to produce several virulence factors. Most of staphylococcal virulence factors are exoproteins which include several types of superantigens and cytolysins as well as antibiotic resistant factors such as $\beta$-lactamases [15]. More than twenty staphylococcal exotoxins are classified as superantigens which cause a variety of human diseases including food poisoning SEs and enterotoxin-like proteins [16], [17]. The superantigens activate several immune cells including dendritic cells, T lymphocytes, antigen-presenting cells, and macrophages [16]. Hemolysin, DNase and coagulase are factors usually associated with SEs secretion [18], [19]. 
Overuse of antibiotics has been reported to be the major factor for the emergence of antibiotic resistant bacteria affecting both human health and the environment [20]-[22]. Antibiotics have been used for treatment of human and animal diseases indiscriminately [23]-[25] and are also used as prophylactic in animal growth [23].

Several investigators reported the emergence of antibiotic-resistant $S$. aureus specifically carbapenems, cephalosporins, linoglycosides, macrolides, penicillin, and streptogramins. Resistant strains of S. aureus for penicillin, streptomycin, erythromycin and tetracyclin are increasing significantly in the last decades [26], [27].

Although it was reported that the elimination of nasal $S$. aureus by $63 \%$ with mupirocin, the emergence of resistant strains to this antibiotic from infected individuals is possible [28]. The increase of mupirocin resistant $S$. aureus as an attempt to eliminate methicillin resistant strains [29].

The aim of this study is to analyze the frequency of infection among food handlers and to relate $S$. aureus virulence factors, such as SEs, blood hemolysis, DNase and antibiotic resistance to food industries and food handlers.

\section{MATERIALS AND METHODS}

\section{A. Selection of Samples}

The selected samples were taken at random from food handlers. A total of 120 samples were collected from food handlers nasal swabs. The swab samples were inoculated on mannitol salt agar MSA and Baired-Parker agar (BP) [30]. The plates were incubated at $37^{\circ} \mathrm{C}$ for 24 hours. Colonies with typical $S$. aureus morphology were selected and biochemically identified by Analytical Profile Index (API) strips, (USA) for Staphylococcus species.

\section{B. Selection of Food Samples and Detection of SES}

Three hundred and sixty samples from three types of food: 120 spring rolls ( $\mathrm{Sr}$ ), 120 sambosa or chicken pie (Chkp) and 120 egg sandwiches (Egs) were analyzed for the presence of $S$ aureus. Ten grams of sample foods were transferred to a sterile stomacher bag and $90 \mathrm{ml}$ of ringer solution was added [2], [31]. The sample was homogenized in a stomacher (Lab. Lemco 400) for $1 \mathrm{~min}$. $1.0 \mathrm{ml}$ from the supernatant was inoculated into salt-meat broth (enrichment media) and incubated at $37^{\circ} \mathrm{C}$ for $24 \mathrm{hrs}$. A loopful from the enrichment media was streaked onto MSA and BP. The plates were incubated at $37^{\circ} \mathrm{C}$ for $24 \mathrm{hrs}$. Colonies with typical S. aureus morphology were identified biochemically using API strips.

$S$. aureus isolates were further analyzed for their virulence factors in relation to their SE production following the standard bacteriological methods [30]. For hemolysis reaction, the isolates were grown on blood agar and incubated for $24 \mathrm{hr}$ at $37^{\circ} \mathrm{C}$. Their ability to hemolyze blood cells was determined. For DNase reaction, bacteria were grown on DNase agar (Oxoid, UK) and incubated for $24 \mathrm{hr}$ at $37^{\circ} \mathrm{C}$. A concentration of $1 \mathrm{~N} \mathrm{HCl}$ was added to the plates. A clear zone around the colonies was considered a positive reaction. The coagulase reaction was done by using the Stphytect Plus test (Oxoid DR 595) [2].

The isolates were screened for $S$. aureus SEs by using an
ELISA kit according to the manufacturer recommendations (TECRA International Pty Ltd, Australia).

\section{Resistance of S. aureus to Antibiotics}

All nasal swab and food sample isolates were screened for thirteen antibiotics using antibiotic susceptibility disk diffusion assay [32]. DST agar (Oxoid, UK) was used. The following antibiotics disks were used: ampicillin 10 $\mu \mathrm{g}$ (Amp), chloramphenicol $30 \mu \mathrm{g} \quad(\mathrm{C})$, clindamycin $2 \mu \mathrm{g}$ (DA), erythromycin $15 \mu \mathrm{g}(\mathrm{E})$, gentamycin $10 \mu \mathrm{g}(\mathrm{CN})$, methicillin

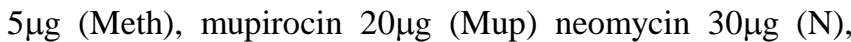
penicillin $10 \mu \mathrm{g}(\mathrm{P})$, streptomycin $10 \mu \mathrm{g}(\mathrm{S})$, tetracycline $30 \mu \mathrm{g}$ (TE), tobramycin $10 \mu \mathrm{g}$ (Tob) and vancomycin 30 $\mathrm{g}$ (VA). Stapylococcus aureus NCTC 6571 was used as a control. The samples were incubated at $37^{\circ} \mathrm{C}$ for $24 \mathrm{~h}$ and the inhibition zones were measured.

\section{RESULTS}

A total of 480 samples was used to isolate $S$. aureus from Ns, Sr, Chkp and Egs. Most of the isolates $(66.2 \%)$ were from Ns, Sr (35.7\%), Chkp (39.3\%) and Eggs (28.7\%) (Fig. 1).

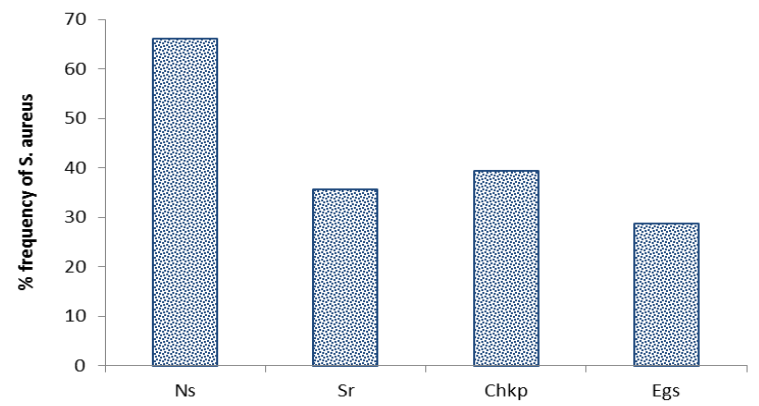

Fig. 1. Percentage of $S$. aureus isolated from food and nasal swab samples. $\mathrm{Ns}=$ nasal swabs, $\mathrm{Sr}=$ spring rolls, $\mathrm{Chkp}=$ chicken pastries and $\mathrm{Egs}=\mathrm{Egg}$ sandwiches.

The enterotoxin producers from Ns samples (30.3\%), $\mathrm{Sr}$ (38.3\%), Chkp (56.1\%) and Egs (49.5\%) (Fig. 2).

Five types of enterotoxins were analyzed. All the 5 types were secreted by the isolates. SEA showed the highest production $(48.9 \%)$ followed by SEB $(43.9 \%)$, SEE (18.7\%) SED (10.5\%) and SEC (6.9\%) (Fig. 3).

The SE types in Sr were as follows: A (48.4\%), B (36.1\%), $\mathrm{C}(3.3 \%), \mathrm{D}(1.3 \%)$ and $\mathrm{E}(10.9 \%)$. Chkp samples were less contaminated with A $(51.3 \%), \mathrm{B}(30 \%), \mathrm{C}(1.2 \%), \mathrm{D}(11.2 \%)$ and $\mathrm{E}(6.3 \%)$. On the other hand, the Egs samples were contaminated with A $(41.8 \%), \mathrm{B}(40.6 \%), \mathrm{C}(3.5 \%), \quad$ D (2.2\%) and $\mathrm{E}$ (6.5\%) (Fig. 4).

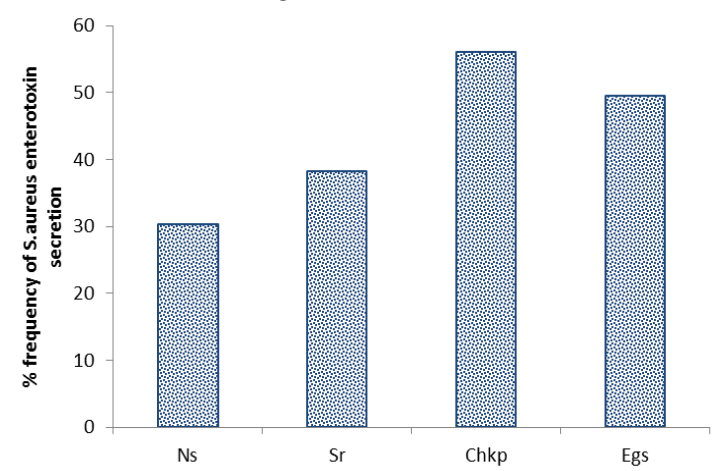

Fig. 2. Percentage of $S$. aureus enterotoxin producers from different samples. $\mathrm{Ns}=$ nasal swabs, $\mathrm{Sr}=$ spring rolls, $\mathrm{Chkp}=$ chicken pastries and Egs $=\mathrm{Egg}$ sandwiches. 


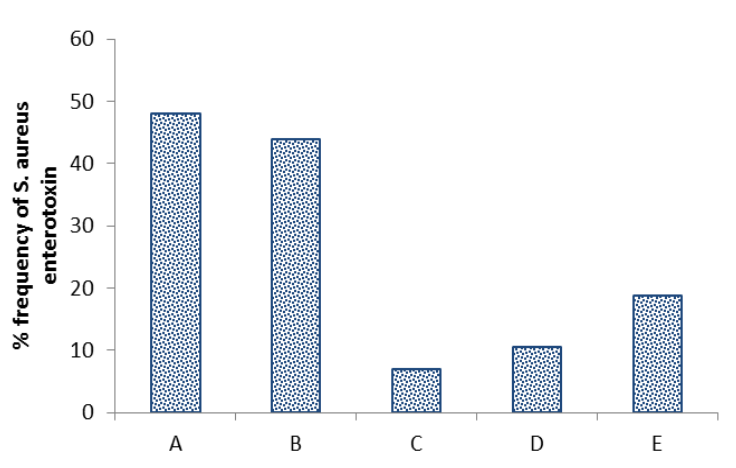

Fig. 3. Percentage of SEs among S. aureus isolates.

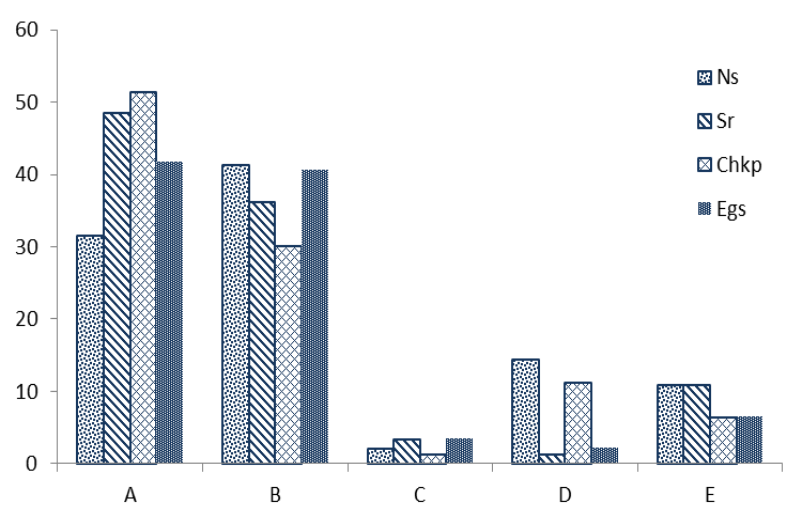

Fig. 4. Percentage frequency of SE types among the S. aureus isolates form diffrent samples. $\mathrm{Ns}=$ nasal swabs, $\mathrm{Sr}=$ spring rolls, $\mathrm{Chkp}=$ chicken pastries and Egs $=$ Egg sandwiches.

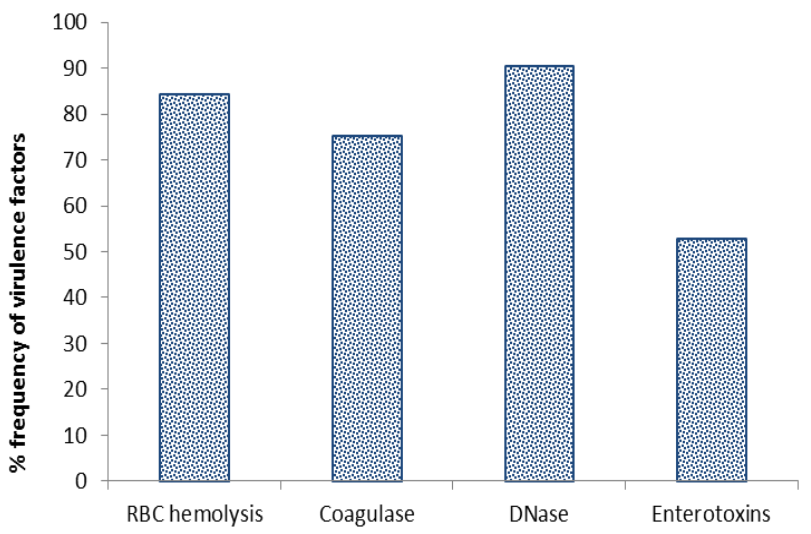

Fig. 5. Frequency percentages of virulence factors of S. aureus isolates.

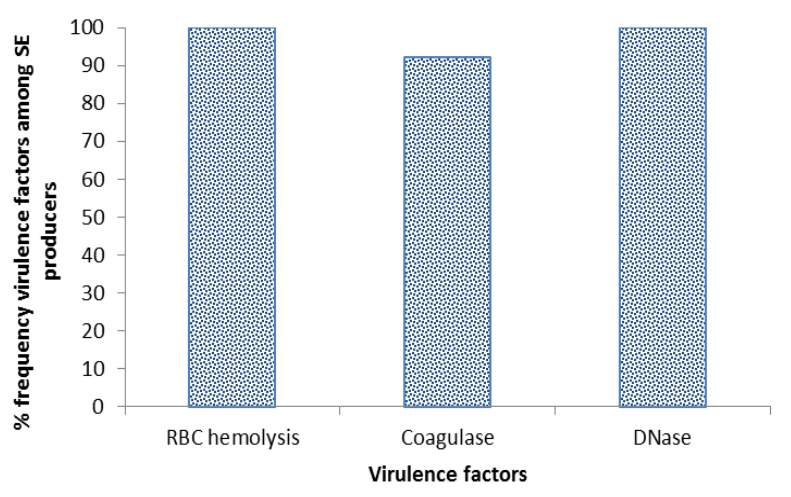

Fig. 6. Virulence percentage frequencies factor among SE producing strains.

The total $S$. aureus isolates showed variation in the virulence factors. Among the isolates, $84.3 \%$ hemolyzed RBCs, $75.2 \%$ produced coagulase. While $90.5 \%$ showed activity for the DNase reaction and only $52.7 \%$ of all isolates secreted SEs (Fig. 5).
The relation of enterotoxin secretion to other virulence factors was analyzed. All of the enterotoxin secreting strains were also positive for hemolysin and DNase enzymes. However, not all strains secreted coagulase enzymes. $92.1 \%$ were coagulase positive (Fig. 6).

The highest resistant was Amp $(86.3 \%)$ followed by $\mathrm{P}$ $(85.93 \%)$ and $\mathrm{Te}(61 \%)$. Only $15.5 \%$ were resistant to Meth, resistance to Tob was the lowest (4.93\%) (Fig. 7).

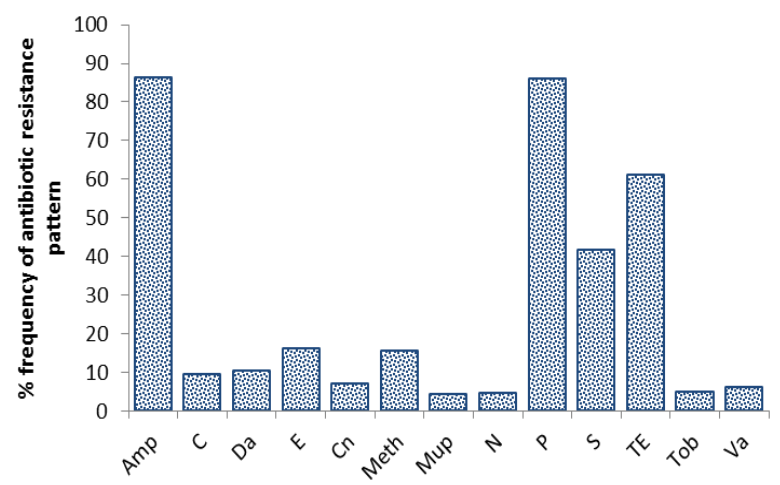

Fig. 7. Frequency of resistance to antibiotics from $S$. aureus isolates. Amp=Ampicillin, $\mathrm{C}=$ Chloramphenicol, DA Clindamycin, $\mathrm{E}=$ Erythromycin, $\mathrm{CN}=$ Gentamycin, Meth=Methicillin, Mup=Mupirocin N=Neomycin,

$\mathrm{P}=$ Penicillin, $\mathrm{S}=$ Streptomycin, $\mathrm{TE}=$ Tetracycline, Tob=Tobramycin, $\mathrm{VA}=$ Vancomycin

Among the resistant strain, about $40.2 \%$ had multiple resistance to two antibiotics. Resistance to one antibiotic was $10.3 \%$. Multiple resistance to 3 antibiotics (13.1\%), 4 (8.4\%) and 5(1.9) (Fig. 8).

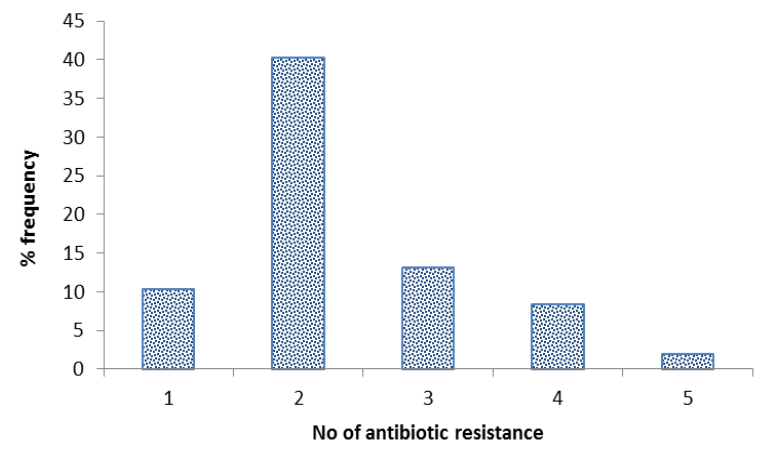

Fig. 8. Percentage frequency relative to the number of antibiotic resistance.

\section{DiscUSSION}

In this study most of the isolates were from nasal swabs. During the last decades several studies were conducted on $S$. aureus in which nasal carriage was the major cause of wound and surgical infections accounting for $40-100 \%$ of staphylococcal infections [33]. In the present investigation it was focused on processed food contamination.

Food handlers were considered to be the main sources of contamination and the cause of staphylococcal food poisoning outbreaks. Food processing cookware was also the source of staphylococcal contamination [2].

In this study, among the tested food handlers, $34 \%$ were asymptomatic $S$. aureus carriers. The percentage of $S$. aureus carriers among the populations differs from one to another. It is well established that nasal carriers of $S$. aureus probably originated from staphylococcal infections [6]. The nasal carriage rate of $S$. aureus in adult populations has been 
reported to be between 30 to $50 \%$, some of which are $\mathrm{SE}$ producers [7]. It was reported that $S$. aureus isolated from animals are different from humans biotypes [34]. The human biotypes were isolates from nasal passages with the highest proportion of SE secretion. In addition it was reported that the source of SEA producing $S$. aureus was mainly from humans and the source for the isolates producing SEC were from animals [35]. This suggests a possible transmission of $S$. aureus biotypes from animals to humans and vice versa.

In this study, most of food handlers were carriers of $S$. aureus. The most contaminated food was chicken pastries and egg sandwiches, thus, these processed foods were considered to be the most common vehicle for $S$. aureus due to substantial human handling during processing and preparation responsible for its contamination. Another study showed that $S$. aureus was present on skin of animals such as chickens contaminating about $24 \%$ of chicken samples examined [36]. Rapid food cooling, proper storage conditions and hygienic care reduce $S$. aureus contaminations [37].

Most of the enterotoxin producers were isolated mainly from chicken pastries, followed by egg sandwiches. Although most of the isolates were from nasal swabs, the isolates from this source were the least SE producers.

$S$. aureus secrets several types of enterotoxins (SEs) which are responsible for causing food poisoning. Different SE serological types have been recognized and designated as SEA, SEB, SEC, SED, SEE, SEG, SHE, SEI and SEJ [1], [6], [7], [10]-[12], [15]. The toxins are superantigens which have the ability to induce diarrhea when ingested [16], [17]. In the present investigation, only SEA, SEB, SEC, SED and SEE were screened. These are the most common $S$. aureus enterotoxins [9].

In the present study, strains producing SEA were the most common, mostly from chicken pastries. Strains producing enterotoxin A are known to be the most frequent in foodborne outbreaks. SEA is a leading cause of staphylococcal food poisoning. SEA is an extremely potent gastrointestinal toxin, with a low as 100ng sufficient to cause toxicity. SEA has two known biological effects. SEA is a super antigen that acts on gastrointestinal cells, stimulating non-antigen-specific $\mathrm{T}$ cells proliferation [9]. Since SEA was detected from nasal swabs, contamination of SEA in chicken pastries was probably from a human source. All the food samples from this study involved extensive preparation and handling, which is a clear indication that the main source of contamination was from nasal samples.

SEB was the second most detected enterotoxin from all samples. Our results are in agreement with Carmo et al, (2002) [38] who reported SEA and SEB are the most frequently detected in both human and food samples. However, in our study, SEC, SED and SEE were the least common enterotoxin detected in both nasal swabs and food samples.

In reference to virulence factors, results indicated that all producing strains were positive for hemolysis and DNase tests, but lesser for coagulase. The enterotoxigenicity of $S$. aureus was found to be highly correlated with their potential production of DNase [39]. Therefore, DNase test was implemented as an index for staphylococci enterotoxigenicity. Furthermore, hemolysis was used in this study, as an indicator for the presence of staphylococci and their enterotoxins. Almost all of $S$. aureus produced coagulase, and were correlated with the production of SEs staphylococcal enterotoxins [18].

Presence of MRSA strains is a serious problem since it can cause outbreak when transmitted from one person to another. In Spain a large outbreak of MRSA resulted from new patients admitted to hospitals with $39 \%$ infected from surgical and skin infections. Most of the strains were resistant to MRSA. MRSA are the common cause of hospital-acquired infections. They are treated with vancomycin, which is often the only drug of choice for severe MRSA infections [32]. In this study $S$. aureus resistance was detected at low frequency in both methicillin and vancomycin.

\section{CONCLUSION}

Staphylococcus aureus strains isolated from nasal swabs secreted a wide range of enterotoxins. The strains from food contaminated with $S$. aureus, were most likely related to human infection. Most of the strains were resistant to the tested antibiotics. The lowest frequency of resistance was exhibited to Tob and $\mathrm{CN}$. There were few strains found to be resistant to vancomycin which is the first drug of choice for treatment of MRSA infections.

This study may enhance public awareness of the importance and appropriate procedures for food processing and care in handling. Improper handling may inflict serious health problems.

\section{REFERENCES}

[1] M. A. Argudín, C. M. Mendoza, and M. R. Rodicio, "Food poisoning and Staphylococcus aureus enterotoxins," Toxins, vol. 2, pp. 1751-1773, 2010.

[2] H. Aycicek, S. Cakiroglu, and T. Stevenson, "Incidence of Staphylococcus aureus in ready-to-eat meals from military cafeterias in Ankara, Turkey," Food Control, vol. 6, pp. 531-534, 2005.

[3] C. Genigeorgis, "Present state of knowledge on staphylococcal intoxication," International Journal of Food Microbiology, vol. 9, pp. 327-360, 1989.

[4] M. Eisenberg, K. Gaarslev, W. Brown, M. Horwitz, and D. Hill, "Staphylococcal food poisoning aboard a commercial aircraft," The Lancet, vol. 306, pp. 595-599, 1975.

[5] R. M. Rooney, E. H. Cramer, S. Mantha, G. Nichols, J. K. Bartram, J. M. Farber, and P. K. Benembarek, "A review of outbreaks of foodborne disease associated with passenger ships: evidence for risk management," Public Health Report, vol. 4, pp. 427-434, 2004.

[6] M. S. Bergdoll, Food borne bacterial pathogen, Marcel Dekker, New York, 1989, pp. 463-523.

[7] B. Normatk, S. Normatk, and A. Teglund, "Staphylococcal protein A inflames the lungs," Natural Medicine, vol. 10, pp. 780-781, 2004.

[8] K. Omoe, M. Ishikawa, Y. Shimoda, D. Hu, S. Ueda, and K. Shinagawa, "Detection of SEG, SEH and SEI genes in Staphylococcus aureus isolates and determination of the enterotoxin productivities of $S$. aureus isolates harboring SEG, SEH or SEI genes," Journal of Clinical Microbiology, vol. 40, pp. 857-860, 2002.

[9] N. Balaban and A. Rasooly, "Staphylococcal enterotoxin," International Journal of Food Microbiology, vol. 61, pp. 1-10, 2000.

[10] S. Munson, M. Tremaine, M. Betley, and R. Welch, "Identification and characterization of staphylococcal enterotoxins types G and I from Staphylococcus aureus," Infection and Immunity, vol. 66, pp. 3337-3348.

[11] Y. Su and A. Wong, "Identification and purification of a new staphylococcal enterotoxin H," Applied and Environmental Microbiology, vol. 61, pp. 1438-1443, 1995.

[12] P. Orwin, D. Leung, H. Donahue, R. Novick, and P. Schlievert, "Biochemical and biological properties of staphylococcal enterotoxin K," Infection and Immunity, vol. 69, pp. 360-366, 2001.

[13] A. Jamshidi, H. R. Kazerani, H. A. Seifi, and E.Moghaddas, "Growth limits of Staphylococcus aureus as a function of temperature, acetic 
acid, $\mathrm{NaCl}$ concentration and inoculum level," Iranian Journal of Veterinary Research, vol. 9, pp. 353-359, 2008.

[14] R. Lanciotti, M. Sinigaglia, F. Gardini, L. Vannini, and M. E. Guerzoni, "Growth/no growth interfaces of Bacillus cereus, Staphylococcus aureus and Salmonella enteritidis in model systems based on water activity, $\mathrm{pH}$, temperature and ethanol concentration," Food Microbiology, vol. 18, pp. 659-668, 2001.

[15] Y. C. Lin and M. L. Peterson, "New insights into the prevention of staphylococcal infections and toxic shock syndrome," Expert Review of Clinical Pharmacology, vol. 3, pp. 753-767, 2010.

[16] A. Bernal, T. Proft, J. D. Fraser, and D. N. Posnett, "Superantigens in human disease," Journal of Clinical Immunology," vol. 19, pp. 149-157, 1999.

[17] P. M. Schlievert, L. C. Case, K. L. Strandberg, T. J. Tripp, Y. C. Lin, and M. L. Peterson, "Vaginal Staphylococcus aureus superantigen profile shift from 1980 and 1981 to 2003, 2004, and 2005," Journal of Clinical Microbiology, vol. 45, pp. 2704-2707, 2007.

[18] G. Normanno, A. Firinu, S. Virgilio et al., "Coagulase-positive staphylococci and Staphylococcus aureus in food products marketed in Italy," International Journal of Food Microbiology, vol. 98, pp.73-79, 2005.

[19] M. M. Dinges, P. M. Orwin, and P. M. Schlievert, "Exotoxins of Staphylococcus aureus," Clinical Microbiology Review, vol. 1, pp. 16-34, 2000.

[20] S. N. Al-Bahry, I. Y. Mahmoud, A. Al-Khaifi, A. E. Elshafie, and A. Al-Harthy, "Viability of multiple antibiotic resistant bacteria in distribution lines of treated sewage effluent used for irrigation," Water Science and Technology, vol. 60, pp. 2939-2948, 2009a.

[21] S. N. Al-Bahry, I. Y. Mahmoud, K. I. Al-Belushi, A. E. Elshafie, A. Al-Harthy, and C. K. Bahkeit, "Coastal sewage discharge and its impact on fish with reference to antibiotic resistant enteric bacteria and enteric pathogens as bio-indicators of pollution," Chemosphere, vol. 77, pp. 1534-1539, 2009b.

[22] S. N. Al-Bahry, I. Y. Mahmoud, and S. K. Al-Musharafi, "Antibiotic resistant bacteria used as bioindicators of environmental pollution produced by tertiary treated sewage effluent," Water Pollution XI, vol. 164, pp. 313-321, 2012.

[23] S. N. Al-Bahry, B. M. Al-Mashani, A. S. Al-Ansari. A. E. Elshafie, and I. Y. Mahmoud, "Escherichia coli tetracycline efflux determinants in relation to tetracycline residues in chicken," Asian Pacific Journal of Tropical Medicine. vol. 6, pp. 718-722, 2013a.

[24] S. N. Al-Bahry, I. Y. Mahmoud, and S. K. Al-Musharafi, "The overuse of tetracycline compounds in chickens and its impact on human health," IPCBEE, vol. 50, pp. 21-25, $2013 \mathrm{~b}$.

[25] I. Y. Mahmoud, S. N. Al-Bahry, and S. K. Al-Musharafi, "Fresh water habitat pollution by treated sewage effluent in relation to multiple-antibiotic-resistant bacteria," APCBEES Procedia, vol. 5, pp 363-367, 2013

[26] A. Onanuga and T. C. Temedie, "Nasal carriage of multi-drug resistant Staphylococcus aureus in healthy inhabitants of Amassoma in Niger delta region of Nigeria," African Health Sciences, vol. 11, pp. 176-181, 2011.

[27] A. E. Waters, T. Contente-Cuomo, J. Buchhagen, C. M. Liu, L. Watson, K. Pearce, J. T. Foster, J. Bowers, E. M. Driebe, D. M. Engelthaler, P. S Keim, and L. B. Price, "Multidrug-resistant Staphylococcus aureus in US meat and poultry," Clinical Infectious Diseases, vol. 52, pp. 1227-1230, 2011.

[28] P. Davey, "Eradication of nasal carriage of Staphylococcus aureus-is it cost-effective?" Journal of Hospital Infection, vol. 40, pp. 1-7, 1998.

[29] J. B. Patel, R. J. Gorwitz, and J. A. Jernigan, "Mupirocin resistance," Clinical Infectious Diseases, vol. 49, pp. 935-941, 2009.

[30] A. C. Sonnenwirth and L. Jarett, Gradwohl's Clinical Laboratory Methods and Diagnosis, vol. 2. $8^{\text {th }}$ Edition. C. V. Mosby Company. ST. Louis, 1980

[31] R. W. Bennett, Staphylococcus aureus, FDA bacteriological analytical manual, USA, 1984.

[32] NCCLS, Performance Standards for Antimicrobial Disk Susceptibility Tests, sixth ed., Approved Standard M2-A6, National Committee for Clinical Laboratory Standards, Wayne, PA. 1997.

[33] M. W. Casewell, "The nose: An underestimated source of S. aureus causing wound infection," Journal of Hospital Infection, vol. 40, pp. 3-11, 1998.

[34] D. Adekeye, "Enterotoxin production by strains of Staphylococcus aureus isolated from animals and main in Nigeria," Veterinary Microbiology, vol. 5, pp. 143-150, 1980.

[35] J. A. Orden, J. Goyache, J. Hernandz, A. Ddomenech, G. Suarez, and E. Gomez-Lucia, "Detection of enterotoxins and TSST-1 secreted by Staphylococcus aureus isolated from ruminant mastitis. Comparison of ELISA and immunoblot," Journal of Applied Bacteriology, vol. 72 pp. 486-489, 1992

[36] M. Eleftheriadou, A. Varnava, M. Metta, A. Nikolaou, and D. Akkelidou, "The microbiological profile of foods in the republic of Cyprus: 1991-2000," Food Microbiology, vol. 19, pp. 463-471, 2002.

[37] M. Bonestroo, B. Kusters, J. De Wit and F. Rombouts, "The fate of spoilage and pathogenic bacteria in fermented sauce-based Egg sandwichs," Food Microbiology, vol. 10, pp. 101-111, 1993.

[38] L. S. Carmo, R. S. Dias, V. R. Linardi, M. J. Sena, D. A. Santos, and E. C. Pena, "Food poisoning due to enterotoxigenic strain of Staphylococcus present in Minas cheese and raw milk in Brazil," Food Microbiology, vol. 19, pp.9-14, 2002.

[39] C. Vernozy-Rozand, C. Mazuy, G. Prevost, C. Lapeyre, M. Bes, Y. Brun, and J. Fleurette, "Enterotoxin production by coagulase-negative staphylococci isolated from goats' milk and cheese," International Journal of Food Microbiology, vol. 30, pp. 271-280, 1996

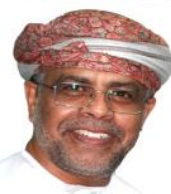

Saif N. Al-Bahry is a full professor in the Department of Biology, College of Science, Sultan Qaboos University, Oman. One of his research interests is the spread of antibiotic resistant bacteria in food and water and the spread of its resistant genes through sewage to environment. Also, $\mathrm{He}$ has used electron microscopy, $\mathrm{x}$-ray microanalysis and image mapping to learn how the microbes are able to penetrate through eggshells and cause infection. His has background in protein analysis, stress proteins expression in microbes and plants. $\mathrm{He}$ is also interested in related areas of bioproducts and bioactive compounds from specific fungi and bacteria. Fungal toxins in food were among those compounds. He has also studied several microbial compounds which have many industrial applications such as cellulases, biopolymers and biosurfactants.

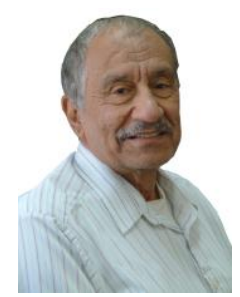

Ibrahim Y. Mahmoud is a full professor in the Department of Biological Sciences and Chemistry, University of Nizwa, Oman. His interest is in physiology and food contaminants. He has published several papers related to food and water contamination. The other interest is in stress physiology, behavioral biology, conservation, homeostatic regulation and reproductive physiology. His experience in dynamic changes in the endocrine system during reproductive and non-reproductive seasons is well known. His has used electron microscopy to study ultrastructura changes and microanalysis in eggshells, embryonic development of fetus subjected to different temperatures and studied microbial invasion in eggs

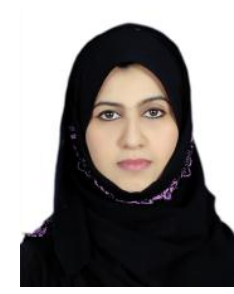

Salma K. Al-Musharafi is an assitant professor in the Department of Applied Biotechnology, Sur College of Applied Sciences, Sur, Oman. She has been conducting research in collaboration with Department of Biology, SQU, as well University of Nizwa. related to food and water contamination. Her contribution has been specifically related to heavy metal environmental pollution and published papers not only heavy metals but also related to microbial contamination. She has used different scientific tools in her study, including electron microscopy. Due to her chemistry back ground, She has collaborated with the same team to study heavy metal pollution in sewage and its impact to the environment. She has published several papers in this area.

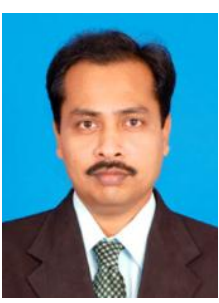

Nallusamy Sivakumar is an assitant professor in the Department of Biology, College of Science, Sultan Qaboos University, Oman. His research area is in food processing. His experience in microbia fermentation and antimicrobial activity of natural products is important in food preseravtion. In microbial fermentation he is working on the possible utilization of different waste materials as alternative and cheap substrates for the production of commercially important microbial products including bactteriocins and antimicrobial activity of natural products, He also studied the effect of different plant extracts and their essential oils on some pathogenic bacteria and their possible mode of action. 